\title{
Preparation of hierarchical porous carbon from waste printed circuit boards for high performance electric double-layer capacitors
}

\author{
Xuan Du, ${ }^{\text {a }}$ Li Wang, ${ }^{\text {ab }}$ Wei Zhao, ${ }^{\text {a }}$ Yi Wang, ${ }^{* a}$ Tao $\mathrm{Qi}^{\mathrm{a}}$ and Chang Ming Li ${ }^{\text {*ac }}$
}

\begin{abstract}
Renewable clean energy and resources recycling have become inevitable choices to solve worldwide energy shortages and environmental pollution problems. It is a great challenge to recycle tons of waste printed circuit boards $(\mathrm{PCB})$ produced every year for clean environment while creating values. In this work, low cost, high quality activated carbons (ACs) were synthesized from non-metallic fractions (NMF) of waste PCB to offer a great potential for applications of electrochemical double-layer capacitors (EDLCs). After recovering metal from waste PCB, hierarchical porous carbons were produced from NMF by carbonization and activation processes. The experimental results exhibit that some pores were formed after carbonization due to the escape of impurity atoms introduced by additives in NMF. Then the pore structure was further tailored by adjusting the activation parameters. Roles of micropores and non-micropores in charge storage were investigated when the hierarchical porous carbons were applied as electrode of EDLCs. The highest specific capacitance of $210 \mathrm{~F} \mathrm{~g}^{-1}$ (at $50 \mathrm{~mA} \mathrm{~g}^{-1}$ ) and

\footnotetext{
${ }^{*}$ a National Engineering Laboratory for Hydrometallurgical Cleaner Production Technology, Institute of Process Engineering, Chinese Academy of Sciences, Beijing 100190,P.R. China. E-mail: wangyi@ipe.ac.cn ${ }^{b}$ College of Petrochemical Technology, Lanzhou University of Technology, Lanzhou 730050, P.R. China ${ }^{c}$ Institute for Clean Energy \& Advanced Materials, Faculty of Materials \& Energy, Southwest University, Chongqing 400715, P.R. China.E-mail:ecmli@swu.edu.cn
} 
excellent rate capability were achieved when the ACs possessing a proper micropores/non-micropores ratio. This work not only provides a promising method to recycle PCB, but also investigates the structure tailoring arts for a rational hierarchical porous structure in energy storage/conversion.

Keywords: Hierarchical porous carbon; Electric double-layer capacitor; Printed circuit board; non-metallic fractions; Energy storage

\section{Introduction}

Electric double-layer capacitors (EDLCs), also known as supercapacitors, are new breakthrough in energy storage devices and have become research hotspots because of their high capacity, great power density and long cycle life [1-3]. Thus EDLCs have been widely used in the information technology industry, electronic devices, electric vehicles, military equipment and so on. Carbon materials are the most commonly used materials for EDLC electrodes due to their high surface area, high conductivity and good physicochemical stability. Up to date, available carbon materials used for EDLCs electrode include activated carbons (ACs) [4], carbon aerogels [5], carbon nanotubes [6] and graphene [7], which possess a variety of microstructures, electrochemical properties and a wide range of costs. However, ACs enjoy the spotlight mainly because of their abundance, low-cost and mass-production. In recent years, to reduce the production cost of ACs, recyclable and waste resources have become attractive precursors to prepare ACs as electrode materials of EDLCs [8-10]. For instance, Jiang et al. [8] prepared ACs for electrochemical supercapacitors from ginkgo shells and the obtained specific capacitance was 
$178 \mathrm{~F} \mathrm{~g}^{-1}$ at $500 \mathrm{mV} \mathrm{s}^{-1}$ within a three-electrode cell. Domingo-Garcia et al. [10] used poly(ethylene terephthalate) (PET) waste from plastic vessels as precursor of carbon electrodes for supercapacitors. PET derived-ACs displayed specific capacitances of $197 \mathrm{~F} \mathrm{~g}^{-1}$ at current density of $1 \mathrm{~mA} \mathrm{~cm}^{-2}$ in $2 \mathrm{~mol} \mathrm{~L}^{-1} \mathrm{H}_{2} \mathrm{SO}_{4}$.

Recycling today is not only driven by the scarcity of resources, but a great response to environmental concerns for a best way to protect all living things. Since the 20th century, the rapid development of electronic technology has led to shorter and shorter electronic product life cycles while discarding more and more waste electrical and electronic equipment (WEEE). It has been reported that 20-50 million tons of WEEE are generated worldwide each year [11,12]. Waste printed circuit boards (PCBs), which are the essential component of WEEE, are composed of various metals and non-metals e.g. thermosetting resins, reinforcing materials, brominated flame retardants (BFRs) and other additives. Therefore, recycling of waste PCBs have drawn much attention because it concerns two principal themes: the protection of environment and the recovery of valuable materials [13-16]. Currently, the metallic fractions (MFs) of waste PCBs can be effectively recycled through mechanical separation methods [16-18]. While the non-metallic fractions (NMFs), which are almost $70 \%$ weight content of waste PCBs, are generally treated by incineration or land filling. Incineration of the NMFs could cause the formation of highly toxic polybrominated dibenzodioxins and dibenzofurans [19,20]. Moreover, land filling of the NMFs would lead to secondary pollution caused by heavy metal residues and BFRs leaching to the groundwater [21]. Therefore, environmental friendly recycling of NMFs from waste PCBs remains a huge challenge. 
It has been reported that the recycling methods of NMFs from waste PCBs mainly include both physical and chemical recycling methods [11]. For the physical method, NMFs can be used as fillers or reinforcing fillers for various products, such as construction materials, decorating agent, adhesives and insulating materials $[20,22,23]$. While the chemical recycling methods of NMFs are employed during and after the stage of chemical separating process for MFs and NMFs. Chemical recycling methods include pyrolysis, gasification, depolymerization with supercritical fluids and hydrogenolytic degradation, etc [24-29]. Among these methods, pyrolysis as a promising recycling method has been widely investigated $[11,28,29]$. Pyrolysis of the organic fraction of PCBs usually leads to the formation of gases, oils and chars, which can be used as chemical feedstocks, fuels, advanced carbonaceous materials (ACMs) and so on [23,30]. For instance, Quan et al. [30] prepared ACMs by pyrolysis oil from glass fiber reinforced epoxy resin in waste PCBs. The BET surface area and micropore volume of the prepared ACMs are $1214 \mathrm{~m}^{2}$ $\mathrm{g}^{-1}$ and $0.41 \mathrm{~m}^{3} \mathrm{~g}^{-1}$, respectively. Although a number of researches have been carried out for handling NMFs in waste PCBs using pyrolysis, few research focused on the use of residue chars.

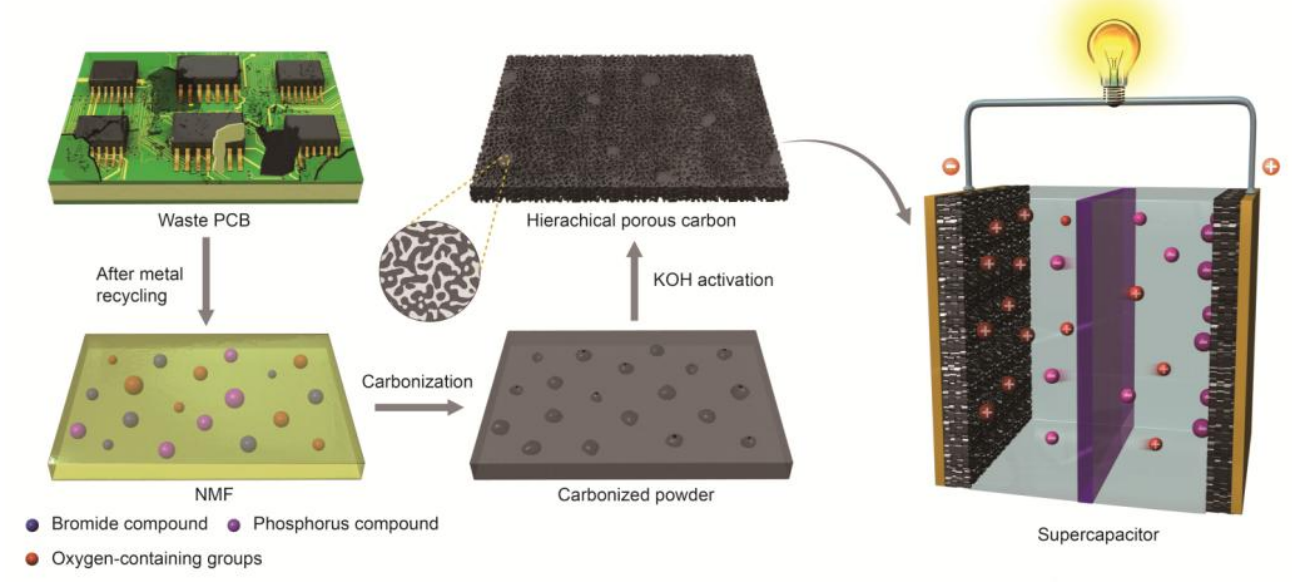

Fig. 1 Scheme for the preparation of NMFs-based AC and its application in EDLC. 
In this paper, for the first time NMFs in waste PCBs are employed as the raw material to produce hierarchical porous carbons used for EDLCs. The preparation of NMFs-based AC and its EDLC application is schematically shown in Fig. 1. The NMFs of waste PCBs contains a high concentration of oxygen-containing groups, providing many reactive sites for activation. Furthermore, NMFs of PCBs usually contain some additives e.g. brominted epoxide resin and triphenyl phosphate as fire retardant. These additives are unstable and can decompose during heat treatment, which can assist in creating additional pores. These characteristics should make NMFs of waste PCBs a promising candidate for producing hierarchical porous carbons with simple preparation process. The ACs derived from NMFs in waste PCBs are applied in EDLCs and excellent rate capability is obtained. This supplies a new approach to recycling the NMFs in waste PCBs avoiding environment pollution caused by their inappropriate disposal. Besides, the use of NMFs of waste PCBs as precursor also can reduce the large-scale production cost of ACs and EDLCs.

\section{Experimental section}

\subsection{Preparation of NMFs-based carbon materials}

Waste PCBs were obtained from Xingsong Flexible Printed Circuit Co., Ltd., Guangdong, China. After separating metals completely, the remained NMFs were washed by deionized water thoroughly and dried. Then ground NMFs with particle size less than $75 \mu \mathrm{m}$ were carbonized under $\mathrm{N}_{2}$ flow at $600{ }^{\circ} \mathrm{C}$ for $1 \mathrm{~h}$ and designated as NMFC6. Portions of NMFC6 sample were chemically activated by $\mathrm{KOH}$ with the $\mathrm{KOH} / \mathrm{sample}$ weight ratio range from 3 to 5 . The mixtures 
of NMFC6 and $\mathrm{KOH}$ were pyrolyzed in a horizontal tubular furnace under $\mathrm{N}_{2}$ flow at $800{ }^{\circ} \mathrm{C}$ for 1 $\mathrm{h}$ with a heating rate of $5^{\circ} \mathrm{C} \mathrm{min}^{-1}$. The activated NMFs (ANMFs) were washed in $1 \mathrm{~mol} \mathrm{~L}^{-1} \mathrm{HCl}$, rinsed in distilled water, filtered and then dried at $80^{\circ} \mathrm{C}$ for $24 \mathrm{~h}$. Then these ACs were labeled as NMFC followed by the carbonization temperature, activation temperature and $\mathrm{KOH} / \mathrm{sample}$ weight ratio; for example, NMFC684 represented carbonization temperature of $600{ }^{\circ} \mathrm{C}$, activation temperature of $800{ }^{\circ} \mathrm{C}$ and $\mathrm{KOH} / \mathrm{sample}$ weight ratio of 4 .

\subsection{Material characterization}

Thermal gravimetric analysis (TGA) coupled with derivative thermogravity analysis (DTG) was conducted with NETzsCH STA449 analyzer in order to determine the pyrolysis behaviors of NMFs. The sample $(5-8 \mathrm{mg})$ was heated from room temperature to $800{ }^{\circ} \mathrm{C}$ with a heating rate of $10{ }^{\circ} \mathrm{C} \min ^{-1}$ in flowing nitrogen. X-ray diffraction (XRD) was carried out on a Rigaku Smartlab system with $\mathrm{CuK} \alpha$ radiation $(\lambda=1.5406 \AA)$. The surface morphologies of NMFs and NMFs-based carbon materials were characterized by field JSM-6700F scanning electron microscopy (SEM). TEM images were obtained with a JEM-2010 microscope operated at $200 \mathrm{kV}$. Fourier transform infrared spectra (FTIR) of NMFs and NMFs-based carbon samples were recorded from an Nicolet Magna-IR 560 FTIR spectrophotometer using the KBr disk method. Thirty-two scans were taken of each sample recorded from the range $4000-800 \mathrm{~cm}^{-1}$ at a resolution of $2 \mathrm{~cm}^{-1}$ in the transmission mode. The $\mathrm{N}_{2}$ adsorption-desorption isotherms of NMFs and NMFs-based carbons were measured at $77 \mathrm{~K}$ using ASAP2020 (Micromeritic, USA) in order to determine the specific surface areas and pore structure parameters. Prior to measurement, samples were outgassed 
overnight at $300^{\circ} \mathrm{C}$ in a vacuum oven.

\subsection{Electrochemical measurements}

The sheet-type electrode was prepared by mixing ANMFs ( $80 \mathrm{wt} . \%)$, acetylene black (10 wt.\%) and PTFE (10 wt.\%), kneading and then rolling to nickel grid that serves as a current collector. Then the electrodes were dried in a vacuum oven at $100{ }^{\circ} \mathrm{C}$ for $12 \mathrm{~h}$ to remove the solvent totally. A couple of the sample electrodes were separated by a glass paper fiber wetted with the $6 \mathrm{~mol} \mathrm{~L}^{-1}$ $\mathrm{KOH}$ solution. The three layers were then pressed in a coin-type cell (LIR 2430). Electrochemical measurements of the sample electrode were determined by two-electrode system without reference electrode using the test cell. Cyclic voltammetry (CV) measurement was performed on CHI 760D electrochemical analyzer (Shanghai, China) controlled by a computer. Cyclic voltammograms were recorded from 0 to $1 \mathrm{~V}$ at various sweep rates. Galvanostatic charge/discharge cycle tests were performed on LAND Celltest (Wuhan, China). The charge and discharge current density were ranged from $50 \mathrm{~mA} \mathrm{~g}^{-1}$ to $1000 \mathrm{~mA} \mathrm{~g}^{-1}$ with cutoff voltage of $0-1 \mathrm{~V}$. The specific capacitance of the supercapacitors can be evaluated from the charge/discharge test together with the following equation:

$$
C_{m}=\frac{I \Delta t}{\Delta V m}
$$

Where $C_{m}$ is the specific capacitance $\left(\mathrm{F} \mathrm{g}^{-1}\right), I$ is the current of the charge-discharge, $\Delta t$ is the time period in seconds for the potential change $\Delta V$, in volts. The $m$ is the mass load of active materials on a single electrode. All the electrochemical measurements were carried out at room temperature. 


\section{Results and discussion}

3.1 Structure and physical properties of NMFs-based carbon materials

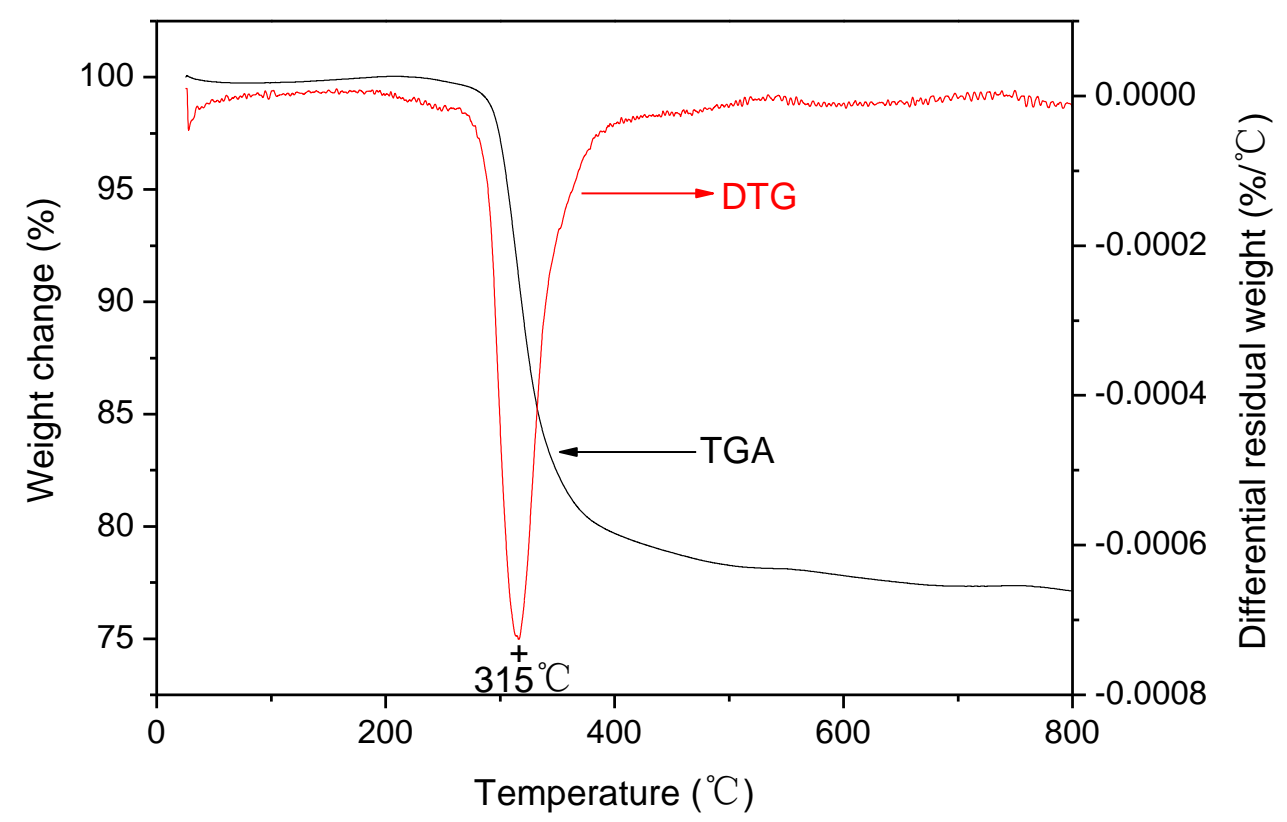

Fig. 2. TGA and DTG curves of NMF.

The thermal stability of NMFs is very important for pyrolysis process. Fig. 2 shows TGA and DTG curves of the NMFs, including the information of maximum degradation rate temperature and mass loss percentage. It can be seen from TGA curve that the NMFs show a sharp weight loss in the temperature range of $250-400{ }^{\circ} \mathrm{C}$. Then, a relatively slow weight loss in the range of $400-600{ }^{\circ} \mathrm{C}$ and a much slower weight loss in the temperature interval of $600-800{ }^{\circ} \mathrm{C}$ are followed. Correspondingly, the DSC curve shows only a high and narrow peak for exothermic effects in the detection temperature range, indicating that many low molecular weight compounds release. Finally, it leaves $77 \%$ solid residue after the TGA experiment, indicating that this precursor is a suitable carbon source material for the preparation of porous carbon. 

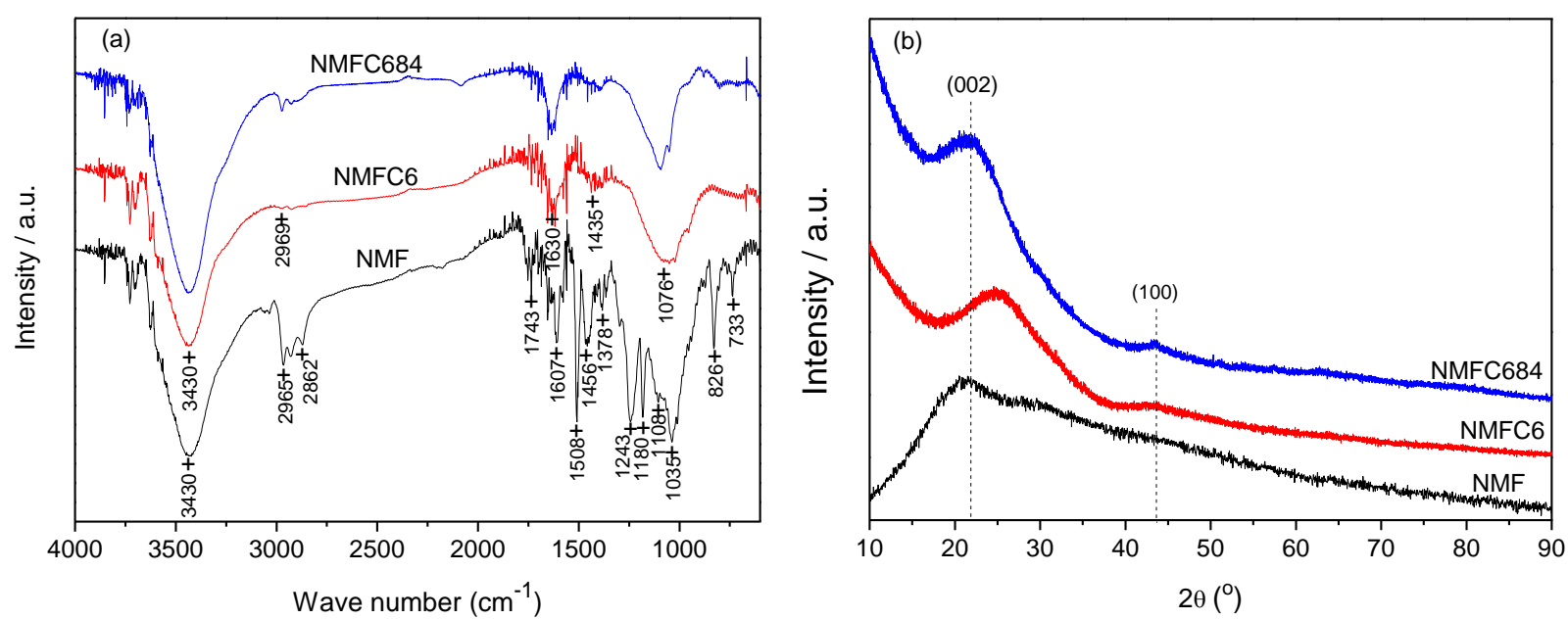

Fig. 3. (a) FT-IR spectra and (b) XRD patterns of NMFs, NMFC6 and NMFC684 (as example of ANMFs).

FT-IR spectra of NMFs, NMFC6 (derived from carbonization of NMFs at $600{ }^{\circ} \mathrm{C}$ ) and NMFC684 (obtained from $\mathrm{KOH}$ activation of NMFC6 at $800{ }^{\circ} \mathrm{C}$ with $\mathrm{KOH} /$ carbon weight ratio of 4) are illustrated in Fig. 3(a). The bands in the spectra can be assigned according to the literatures [31]. Firstly, as for the spectrum of raw material, NMFs, the peak at $3430 \mathrm{~cm}^{-1}$ corresponds to O-H stretching. The peaks at 2965 and $2862 \mathrm{~cm}^{-1}$ correspond to C-H stretching in benzene ring skeleton. The peak at $1743 \mathrm{~cm}^{-1}$ is assigned to $\mathrm{C}=\mathrm{O}$ stretching in ketones. The characteristic stretching vibration of $\mathrm{C}=\mathrm{C}$ double bonds in benzene ring skeleton appears at 1607, 1508, 1456 $\mathrm{cm}^{-1}$, C-H deformation vibration of methyl appears at $1378 \mathrm{~cm}^{-1}$. The band at $1243 \mathrm{~cm}^{-1}$ corresponds to P-O-Ar stretching in triphenyl phosphate. The bands at $1180,1108,1035 \mathrm{~cm}^{-1}$ correspond to C-O stretching vibration of aryl- and aryl ester-based ethers in epoxide resin. The peak at $826 \mathrm{~cm}^{-1}$ is due to the adsorption of epoxy group. The peak at $733 \mathrm{~cm}^{-1}$ can be assigned to $\mathrm{C}-\mathrm{Br}$ stretching. The results indicate that the NMFs mainly contain brominted epoxide resin, 
together with triphenyl phosphate as fire retardant. Whereas, as for NMFC6 and NMFC684, the position of peaks are in accordance with the data obtained by carbon materials analysis [32,33]. XRD patterns of the samples are shown in Fig. 3(b). The XRD profiles of the original NMFs show only a broad peak at a scattering angle of about $20^{\circ}$. After carbonization at $600{ }^{\circ} \mathrm{C}$, there are two diffraction peaks around $2 \theta=25^{\circ}, 44^{\circ}$ in the spectrum, corresponding to the diffraction of (002) and (100) planes, respectively. The (002) peak of NMFC684 shift to smaller angle (around 22\%), suggesting its 'turbo-static' structure. Therefore, it can be deduced from XRD together with FT-IR results that the structure of the NMFs has been disrupted and transformed into typical structure of carbon materials after carbonization and activation.
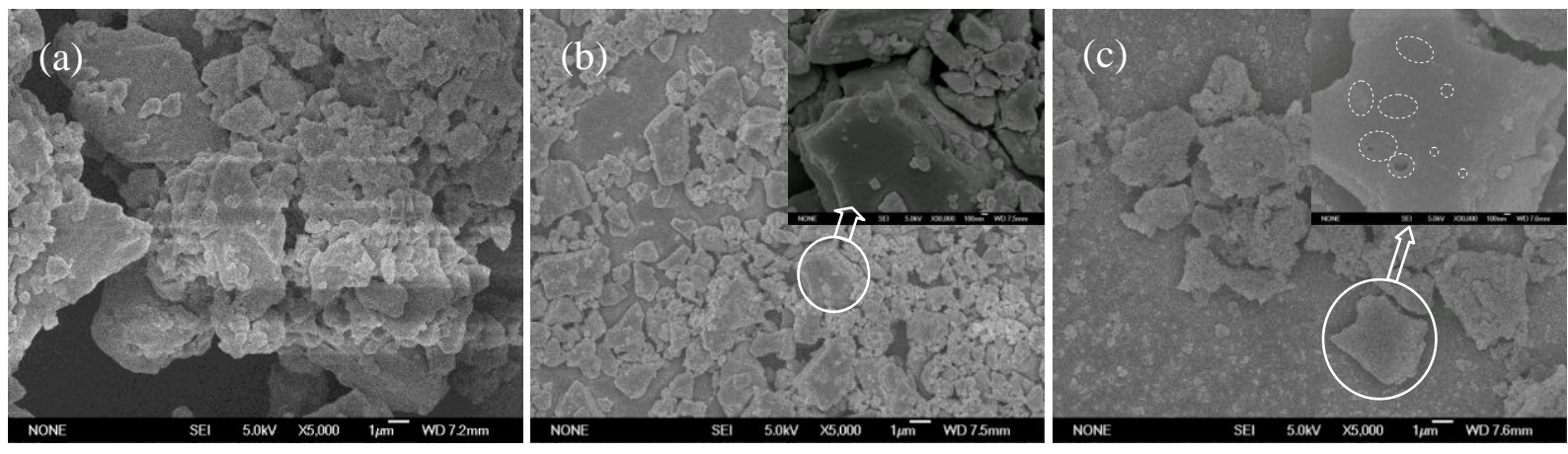

Fig. 4 SEM photographs of (a) NMFs, (b) NMFC6 and (c) NMFC684 (as example of ANMFs).

Fig. 4 depicts the surface morphologies of raw NMFs, NMFC6 and NMFC684. SEM images of NMFC683 and NMFC685 are not presented here because of the similarity to NMFC684. One can see that NMFs have quite a smooth surface without any void in Fig. 4(a). After carbonization, there is no evident change appears on the surface of NMFC6 (Fig. 4 (b)) but some layered texture appears at the edge of grains. Nevertheless, it can be noticed that a heterogeneous surface for 
NMFC684 in Fig. 4(c), which clearly demonstrates a cracked and pitted surface morphology. This phenomenon can be attributed to the etching of $\mathrm{KOH}$.

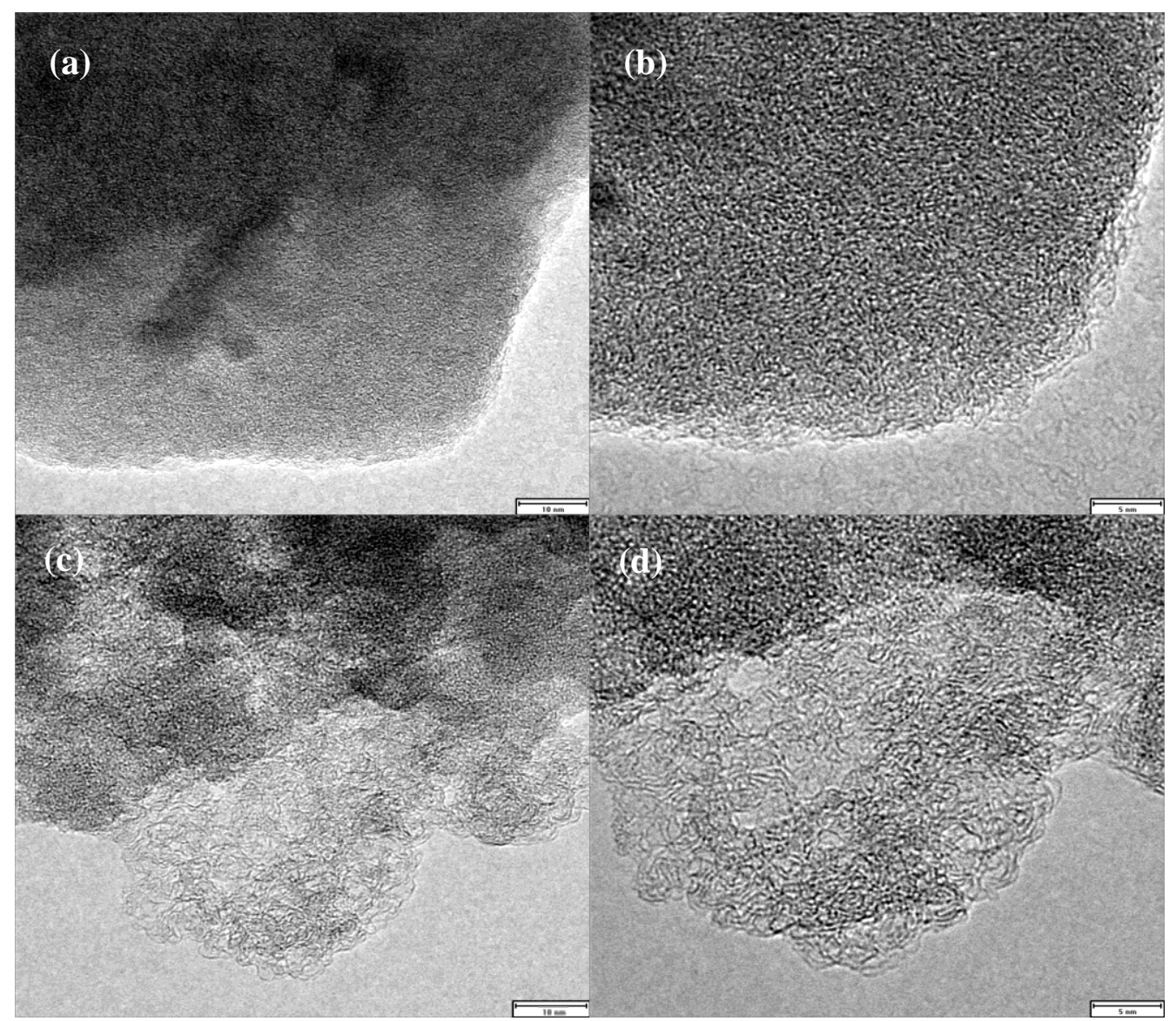

Fig. 5. (a) TEM image of NMFC6 particles, (b) high-resolution micrograph of sample NMFC6, (c) TEM image of NMFC684 particles and (d) high-resolution micrograph of sample NMFC684.

TEM images of the carbon samples are given in Fig. 5. It can be easily seen from Fig. 5 that NMFC684 (Fig. 5(c)-(d)) possesses many pores so that the structure of NMFC684 is more loose than NMFC6 (Fig. 5(a)-(b)). In addition, NMFC684 is amorphous and has a highly disordered pore structure. Furthermore, Fig. 5(c) and (d) tell that the plenty micropores are connecting with the mesoporous channel walls, indicating the formation of a continuous three-dimensional pore 
network [34]. This result proves the SEM results that NMFs-based ACs have porous structure after $\mathrm{KOH}$ activation.
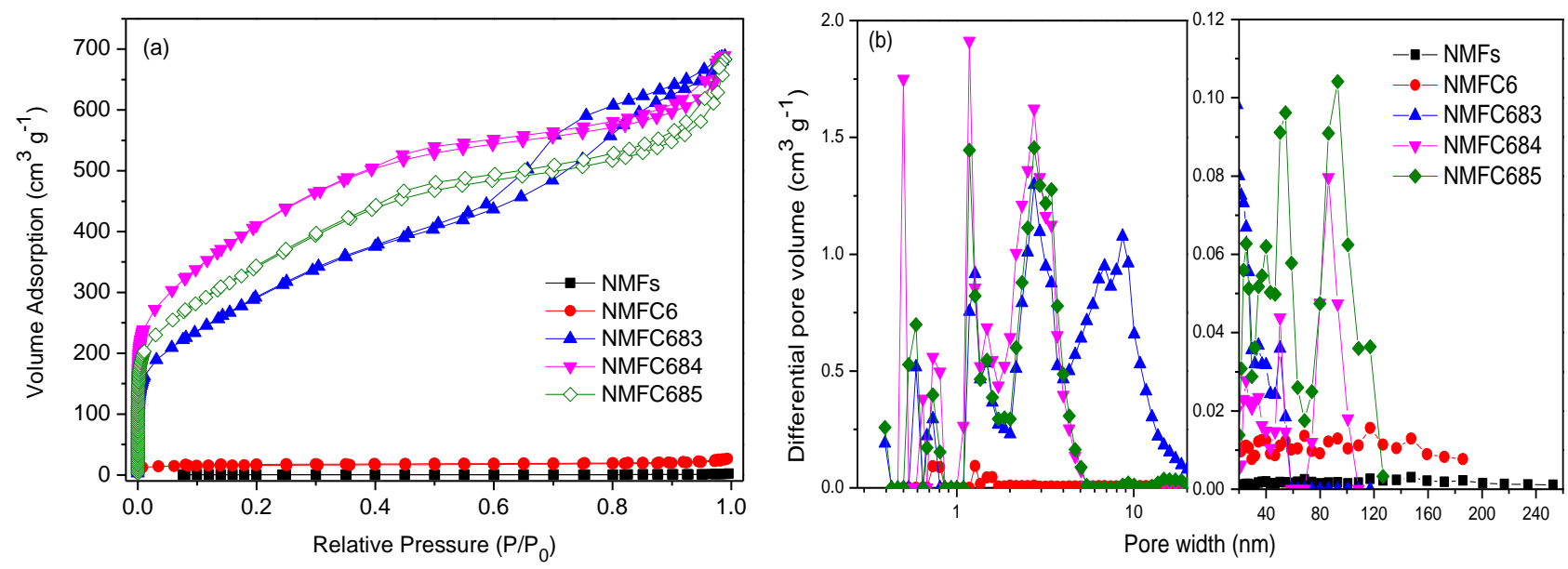

Fig. 6. $N_{2}$ adsorption isotherms (a) and pore size distribution (b) of NMFs, NMFC6 and ANMFs.

To understand the influence of carbonization and activation processes on the development of pore structure in ACs prepared from NMFs, the obtained samples were characterized by $\mathrm{N}_{2}$ adsorption-desorption analysis. The nitrogen sorption isotherms and pore size distributions of "un-treated" NMFs and NMFs-based ACs are depicted in Fig. 6(a) and (b), respectively. As shown in Fig. 6(a), the adsorption volume of raw NMFs is almost zero, which indicates that NMFs is nonporous material. After carbonization of NMFs, NMFC6 shows typical type I isotherm suggests the microporous character, which maybe caused by the release of some low molecular weight compounds (for instance the oxygen-containing groups and the additives of NMFs). NMFC6 shows small $\mathrm{N}_{2}$ adsorption volume suggesting that it has a few of pores inside. As for the activated samples (NMFC683, NMFC684 and NMFC685), the shapes of isotherms gradually change with the variation of activation conditions. On the one hand, it is evident that $\mathrm{N}_{2}$ uptakes of the activated carbon samples increase at first then decrease with the increase of $\mathrm{KOH} / \mathrm{carbon}$ 
weight ratio. On the other hand, the isotherms of activated carbon samples are incorporated by both a broader knee and more obvious hysteresis loop, which is a combination of type I and IV isotherm according to the IUPAC classification $[35,36]$. The broad knee results generally from the co-existence of both micropores and mesopores, and the hysteresis loop also indicates the presence of mesopores. It also can be noticed from Fig. 6(a) that the shape of NMFC683 is most close to type IV isotherm, which illustrates that the mesopores content of NMFC683 is the most among three activated carbon samples.

The pore size distributions of all the samples are displayed in Fig. 6(b). As expect from $\mathrm{N}_{2}$ adsorption-desorption analysis, sample NMFs has very little pores. NMFC6 shows some pores after pyrolysis caused by the decomposing of the oxygen-containing groups and the additives of NMFs. Furtherly, the samples activated by KOH show much more developed pore structure. As can be seen from Fig. 6(b), the pore distributions and the amount of pores in different regions of the activated samples changed markedly with the variation of activation conditions. Firstly, as for NMFC683, there are two outstanding peaks located at around $2.8 \mathrm{~nm}$ and $9 \mathrm{~nm}$, revealing that it is dominanted by mesopores. This is corresponding well to the analysis of $\mathrm{N}_{2}$ adsorption isotherm. Then, the pore distribution shifts to smaller pore size with rising $\mathrm{KOH} /$ carbon weight ratio. As a result, mesopores content of sample NMFC684 declines sharply while two micropores fractions spring up (one is near $0.5 \mathrm{~nm}$ and another is near $1.2 \mathrm{~nm}$ ). The mesopores distribute mainly around $2.8 \mathrm{~nm}$. At the same time, two peaks belonging to macropores range are emerged at around $51 \mathrm{~nm}$ and $87 \mathrm{~nm}$, which would act as ion-buffering reservoirs to ensure adequate penetration of the electrolyte into the electrode materials [37]. When the $\mathrm{KOH} /$ carbon weight ratio increases to 5, the 
amount of micropores reduces rapidly together with some mesopores. In contrast, there is some increase of macropores. Therefore, the $\mathrm{KOH} / \mathrm{carbon}$ weight ratio is an important factor to influence the pore structure of NMFs-based activated carbon materials, which is believed to affect the electrical properties (e.g. the specific capacitance and charge-discharge rate).

The carbon-yield and porous properties of all the samples are listed in Table 1. It can be seen that the carbon-yield decreases monotonously after carbonization and activation with increasing the $\mathrm{KOH} / \mathrm{carbon}$ weight ratio. The surface area, total pore volume, micropore volume increase but average pore diameter shrinks with increasing the $\mathrm{KOH} /$ carbon weight ratio up to 4 . These results suggest that with the increase of $\mathrm{KOH} / \mathrm{carbon}$ weight ratio the gasification of carbon will result the opening of closed pores as well as deepening and widening of the micropores. When the $\mathrm{KOH} /$ carbon weight ratio rises to 5, a downward trend in the surface area, total pore volume, and micropore volume is observed. Nevertheless, the mesopore volume and average pore diameter become larger. This is due to that over-activation $(\mathrm{KOH} /$ carbon weight ratio of 5) causes the destruction of some micropores, leading to an overall loss of surface area and pore volume.

\subsection{Electrochemical performances of NMFs-based ACs electrodes}

The electrochemical measurements of sample NMFs and NMFC6 were ignored because of the tiny pore volume according to the $\mathrm{N}_{2}$ isotherm analysis. The CVs for the NMFs-based ACs electrodes (NMFC683, NMFC684 and NMFC685) were measured at different scan rates (from 1 $\mathrm{mV} \mathrm{s}^{-1}$ to $2000 \mathrm{mV} \mathrm{s}^{-1}$ ) in $6 \mathrm{~mol} \mathrm{~L}^{-1} \mathrm{KOH}$ solution. Fig. 7 displays $\mathrm{CV}$ curves of all the activated carbon samples at scan rates of $2 \mathrm{mV} \mathrm{s}^{-1}, 20 \mathrm{mV} \mathrm{s}^{-1}, 1000 \mathrm{mV} \mathrm{s}^{-1}$ and $2000 \mathrm{mV} \mathrm{s}^{-1}$ as the selected 
examples. First of all, it can be seen in Fig. 7(a)-(c) that the CV curves of the three ANMFs materials exhibit a nearly rectangular shape, and over most of the potential range the currents are nearly constant, which implies the ideal capacitive behavior. There is no evidence for any redox currents on both positive and negative sweeps in the chosen potential range, which is the typical characteristic for electric double layer capacitor. Secondly, all the tested samples preserve good shape of voltammetry characteristics at scan rates varing from $1 \mathrm{mV} \mathrm{s}^{-1}$ to $1000 \mathrm{mV} \mathrm{s}^{-1}$. While, only NMFC683 keeps non-deforming apparently when scan rate is up to $2000 \mathrm{mV} \mathrm{s}^{-1}$ (Fig. 7(d)). It reveals that NMFC683, possessing the most abundant mesopores among all the samples (Fig. 6(b)), has better ionic accessibility than the others. It suggests that NMFC683 is more suitable for quick charge/discharge operations [8]. But the responding current exposes that the capacitance of NMFC683 is much lower than that of NMFC684.
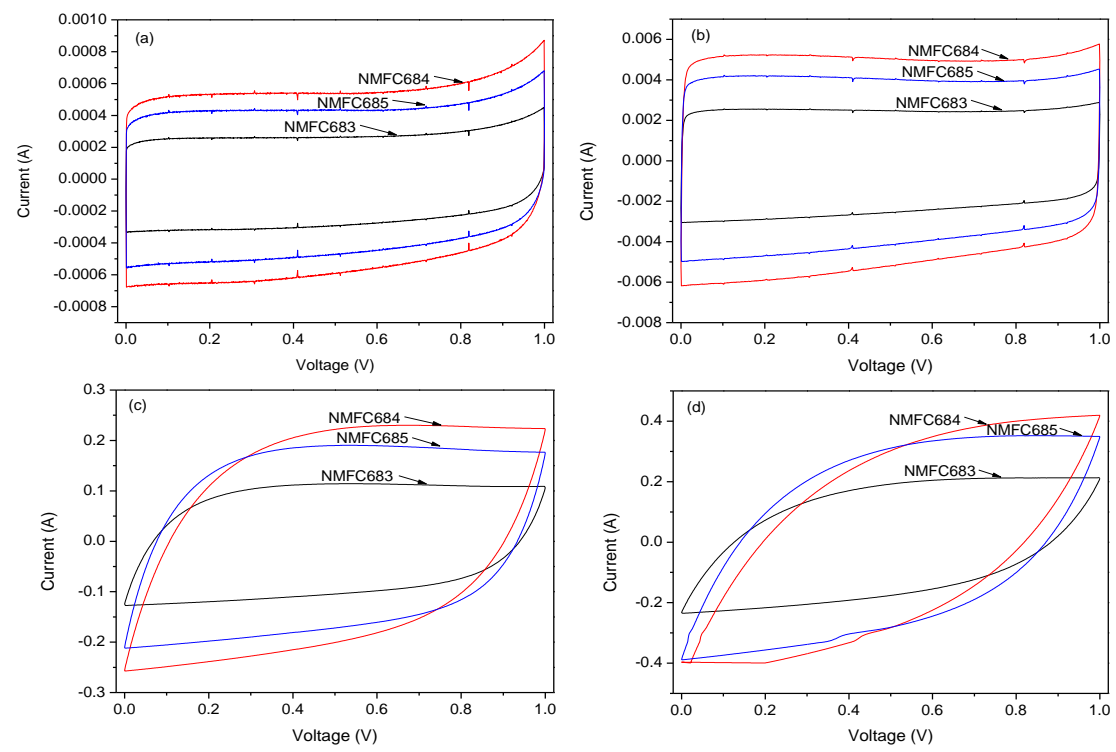

Fig. 7 Cyclic voltammograms of the symmetric two-electrode capacitors assembled with ANMFs in $6 \mathrm{~mol} \mathrm{~L}^{-1} \mathrm{KOH}$ aqueous electrolyte at different scan rate of (a) $2 \mathrm{mV} \mathrm{s}^{-1}$, (b) $20 \mathrm{mV} \mathrm{s}^{-1}$, (c) 1000 $\mathrm{mV} \mathrm{s}^{-1}$ and (d) $2000 \mathrm{mV} \mathrm{s}^{-1}$. 

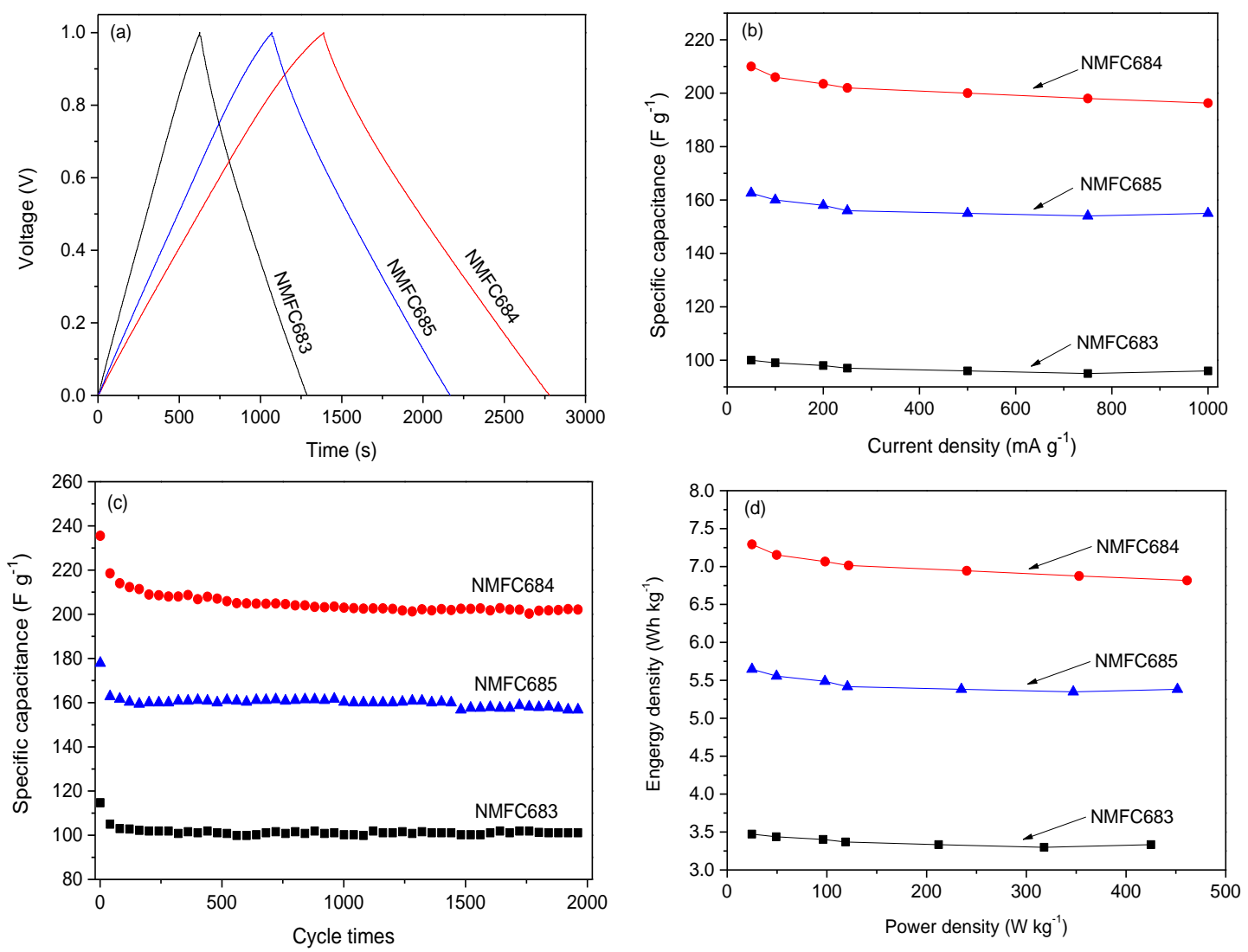

Fig. 8. (a) Charge/discharge curves of ANMFs obtained at current density of $50 \mathrm{~mA} \mathrm{~g}^{-1}$, (b) specific capacitance at various current densities for ANMFs samples, (c) cycling performance of ANMFs at current density of $100 \mathrm{~mA} \mathrm{~g}^{-1}$, (d) Ragone plots for activated carbons obtained from NMFs. Specific energy and specific power are based on the mass of active electrode material.

Typical charge-discharge curves at current density of $50 \mathrm{~mA} \mathrm{~g}^{-1}$ are given in Fig. 8(a). Almost linear charge and discharge curves are observed, which correspond to those of the ideal EDLC.

The results are in good agreement with those obtained from the CV tests. The mass-specific capacitances of ANMFs are shown in Table 1. It can be seen that the specific capacitance is proportionate to the specific surface area and micropore volume.

The charge/discharge performance at high rate is often chosen to estimate the capacitive properties. The higher the capacitance retains at high rate, the better the capacitive performance will be. The gravimetric specific capacitances at different current densities are listed in Fig. 8(b) to 
help estimating the rate properties. Here it can be clearly seen that, sample NMFC684 has the highest capacitance at both low and high current density. There is a progressive decline of specific capacitance with the specific current increasing to $1000 \mathrm{~mA} \mathrm{~g}^{-1}$, the specific capacitance of sample NMFC684 retains as high as $94 \%$ of its initial capacitance; in contrast, sample NMFC683 has 96 $\%$ of its initial capacitance but the lowest value retained among these ANMFs samples. Overall, the specific capacitance of these samples follows the order of NMFC684>NMFC685>NMFC683 while the order of capacitance retention is NMFC683>NMFC685>NMFC684. These results manifest that the proper pore structrue is crucial for the application of carbon electrode material in EDLCs. The existence of mesopores and macropores would benefit to quick transportation of electrolyte ions to the bulk of the material. At the same time, the abundance of micropores play significant roles in enhancing the capacitance of the carbon material. Consequently, the electrode with high specific surface area and proper porous structure, like sample NMFC684, would introduce high specific capacitance and give proper consideration to capacity retention at higher current density. This result agrees well with that derived from the CV studies.

The charge/discharge cycle stability of electrode materials also has practical importance for EDLC applications. To clarify the cycling stability of ANMFs, all the samples endured 2000 charge-discharge cycles, with a current density of $100 \mathrm{~mA} \mathrm{~g}^{-1}$ and voltage from 0 to $1.0 \mathrm{~V}$. The values of specific capacitance as a function of cycle number are given in Fig. 8(c). According to Fig. 8(c), although sample NMFC683 and NMFC685 show slightly better capacity retention than NMFC684, their specific capacitances are much lower than that of NMFC684. This can be attributable to the relationship between the specific capacitance and pore structure of electrode 
material as discussed above. But altogether, the measured capacity retentions are all above $86 \%$ for the ANMFs after 2000 cycles, which exhibit good electrochemical reproducibility. This result clearly indicates that the electrodes assembled by activated NMFs are stable under these long-term charge-discharge cycles.

The energy density, $\mathrm{E}=\left(C U_{0}^{2} / 2\right)$, and power density, $\mathrm{P}=(E / t)$, are two important parameters that characterize the electrochemical performance of an electrochemical capacitor, where $\mathrm{U}_{0}$ is the potential at the end of charge (V) and $t$ is the discharge time (s). Fig. 8(d) presents a Ragone plot, which relates the energy density to the power density of the supercapacitors. Noticeably, the highest energy density of $7.3 \mathrm{Wh} \mathrm{kg}^{-1}$ is obtained with NMFC684, i.e., the carbon with the highest specific capacitance. With increasing specific power, the benefits of mesopores and macropores in the carbon materials are clearly demonstrated by the stable performances of NMFC683 and NMFC685, which retain over 95\% of their initial energy density at power density around $450 \mathrm{~W}$ $\mathrm{kg}^{-1}$

\section{Conclutions}

A new approach to recycling the NMFs from waste PCBs was innovated, which has potential application in EDLCs. The hierarchical porous carbon materials were prepared by carbonization of the NMFs, followed by activation with $\mathrm{KOH}$. The results indicate that the oxygen-containing groups and the additives of NMFs left some pores after they volatilized out during carbonization. Then the pore structure were developed further under $\mathrm{KOH}$ activation. The surface area and micropore volume increase firstly and then decrease with the increase of the ratio of $\mathrm{KOH} /$ carbon. 
The electrochemical measurements show that micropores play a significant role in enhancing the capacitance of carbon materials and the existence of mesopores and macropores would benefit to quick transportation of electrolyte ions in the porous electrode. Hence, the rational porous structure together with high surface area specific capacitance produces the higher specific capacitance as well as good capacity retention at high current density. The obtained samples present the highest capacitance value of $210 \mathrm{~F} \mathrm{~g}^{-1}$ at current density $50 \mathrm{~mA} \mathrm{~g}^{-1}$. When the current density increases to $1000 \mathrm{~mA} \mathrm{~g}^{-1}$, the capacitance is still as high as $196 \mathrm{~F} \mathrm{~g}^{-1}$. This indicates NMFs-based ACs have superior rate capability and superior capacitive behaviors as electrode materials for EDLCs. Therefore, this study not only can provide a new approach to alleviate environment pollution caused by the inappropriate disposal of waste PCBs but also can improve the added value of residue chars of waste NMFs as well as reduce the production cost of ACs using for EDLCs with high rate property. This work also investigates the structure tailoring arts for a rational hierarchical porous structure in energy storage/conversion and the pore structure effect on capacitive behaviour.

\section{Acknowledgements}

The authors gratefully acknowledge the support by National Natural Science Foundation of China (51302264) and the projects of National Science Foundation for Distinguished Young Scholars of China (51125018), as well as One Hundred Talent Program of Chinese Academy of Sciences.

\section{References}


[1] G. P. Wang, L. Zhang, J. J. Zhang, Chem. Soc. Rev. 41 (2012) 797-828.

[2] L. L. Zhang, X. S. Zhao, Chem. Soc. Rev. 38 (2009) 2520-2531.

[3] Y. P. Zhai, Y. Q. Dou, D. Y. Zhao, P. F. Fulvio, R. T. Mayes, S. Dai, Adv. Mater. 23 (2011) $4828-4850$.

[4] Y. H. Wen, G. P. Cao, Y. S. Yang, J. Power Sources 148 (2005) 121-128.

[5] J. Z. Wang, M. M. Chen, C. Y. Wang, J. Wang, J. M. Zheng, Mate. Lett. 68 (2012) 446-449.

[6] X. Geng, F. Li, D. W. Wang, H. M. Cheng, New Carbon Materials 28 (2013) 146-150.

[7] J. Yan, J. P. Liu, Z. J. Fan, T. Wei, L. J. Zhang, Carbon 50 (2012) 2179-2188.

[8] L. Jiang, J. W. Yan, L. X. Hao, R. Xue, G. Q. Sun, B. L. Yi, Carbon 56 (2013) 146-154.

[9] M. C. Liu, L. B. Kong, C. Lu, X. M. Li, Y. C. Luo, L. Kang, Rsc Adv. 2 (2012) 1890-1896.

[10] M. Domingo-Garcia, J. A. Fernandez, M. C. Almazan-Almazan, F. J. Lopez-Garzon, F. Stoeckli, T. Centeno, A. J. Power Sources 195 (2010) 3810-3813.

[11] J. Y. Guo, J. Guo, Z. M. Xu, J. Hazard Mater. 168 (2009) 567-590.

[12] K. Huang, J. Guo, Z. M. Xu, J. Hazard Mater. 164 (2009) 399-408.

[13] J. R. Cui, L. F. Zhang, J. Hazard Mater. 158 (2008) 228-256.

[14] W. Z. He, G. M. Li, X. F. Ma, H. Wang, J. W. Huang, M. Xu, C. J. Huang, J. Hazard Mater. 136 (2006) 502-512.

[15] M. Goosey, R. Kellner, Circuit World 29 (2003) 33-37.

[16] C. Eswaraiah, T. Kavitha, S. Vidyasagar, S. S. Narayanan, Chem. Eng. Process. 47 (2008) $565-576$.

[17] J. R. Cui, E. Forssberg, J. Hazard Mater. 99 (2003) 243-263. 
[18] H. Y. Kang, J. M. Schoenung, Resour. Conserv. Recy. 45 (2005) 368-400.

[19] B. H. Robinson, Sci. Total Environ. 408 (2009) 183-191.

[20] C. V. Owens, C. Lambright, K. Bobseine, B. Ryan, L. E. Gray, B. K. Gullett, V. S. Wilson, Environ. Sci. Technol. 41 (2007) 8506-8511.

[21] D. L. Wang, Z. W. Cai, G. B. Jiang, A. Leung, M. H. Wong, W. K. Wong, Chemosphere 60 (2005) 810-816.

[22] J. Guo, Q. L. Rao, Z. M. Xu, J. Hazard Mater. 153 (2008) 728-734.

[23] Y. H. Zheng, Z. G. Shen, C. J. Cai, S. L. Ma, Y. S. Xing, J. Hazard Mater. 163 (2009) 600-606.

[24] T. Yamawaki, Fire Mater. 27 (2003) 315-319.

[25] H. Tagaya, Y. Shibasaki, C. Kato, J. Kadokawa, B. Hatano, J. Mater. Cycles. Waste 6 (2004) $1-5$.

[26] D. Braun, W. von Gentzkow, A. P. Rudolf, Polym. Degrad. Stabil. 74 (2001) 25-32.

[27] G. Grause, M. Furusawa, A. Okuwaki, T. Yoshioka, Chemosphere 71 (2008) 872-878.

[28] J. Guan, Y. S. Li, M. X. Lu, J. Anal. Appl. Pyrolysis 83 (2008) 185-189.

[29] H. L.Chiang, K. H. Lin, M. H. Lai, T. C. Chen, S. Y. Ma, J. Hazard Mater. 149 (2007) 151-159.

[30] C. Quan, A. M. Li, N. B. Gao, J. Hazard Mater. 179 (2010) 911-917.

[31]A. I. Balabanovich, A. Hornung, D. Merz, H. Seffert, Polym. Degrad. Stabil. 85 (2004) 713-723.

[32] H. Deng, G. X. Li, H. B. Yang, J. P. Tang, J. Y. Tang, Chem. Eng. J. 163 (2010) 373-381. 
[33] A. N. A. El-Hendawy, J. Anal. Appl. Pyrolysis 75 (2006) 159-166.

[34] Y. Guo, Z. Q. Shi, M. M. Chen, C. Y. Wang, J. Power Sources 252 (2014) 235-243.

[35] M. A. Nahil, P. T. Williams, Biomass Bioenerg. 37(2012) 142-149.

[36] R. Farma, M. Deraman, A. Awitdrus, I. A. Talib, E. Taer, N. H. Basri, J. G. Manjunatha, M. M. Ishak, B. N. M. Dollah, S. A. Hashmi, Bioresour. Technol. 132 (2013) 254-261.

[37] D. W. Wang, F. Li, M. Liu, G. Q. Lu, H. M. Cheng, Angew. Chem. Int. Ed. 47 (2008) 373-376. 